\title{
REVERSE ENGINEERING AND 3D MODELLING FOR DIGITAL DOCUMENTATION OF MARITIME HERITAGE
}

\author{
F. Menna ${ }^{a, b}$, E. Nocerino ${ }^{\text {a, c }}$, A. Scamardella ${ }^{\text {a }}$ \\ ${ }^{a}$ Dept. of Applied Sciences, Parthenope University of Naples, Centro Direzionale Isola C4, Napoli, Italy - \\ (fabio.menna, erica.nocerino, antonio.scamardella)@uniparthenope.it \\ b 3D Optical Metrology Unit, Bruno Kessler Foundation (FBK), Trento, Italy - \\ fmenna@fbk.eu, web: http://3dom.fbk.eu \\ ${ }^{a}$ Dept. of Naval Engineering, Federico II University of Naples, Via Claudio 21 Napoli, Italy - \\ erica.nocerino@unina.it
}

KEY WORDS: Photogrammetry, Laser Scanning, Maritime Cultural Heritage, 3D Modelling, Reverse Engineering.

\begin{abstract}
Since 2003, Barcelona charter has highlighted the importance of digital recording of historic ships and maritime heritage in general. Despite this has been stressed with emphasis, three dimensional modelling of maritime cultural heritage is still not usual as for archaeology and architecture. Three-dimensional modelling in the maritime heritage needs particular requirements. Objects to be recorded range from small replicas in maritime museums up to full-scale vessels still in operation. High geometric accuracy, photorealism of final model and faithful rendering of salient details are usually needed, together with the classical requisites characterising the 3D modelling-from-reality process, i.e. automation, low cost, reliability and flexibility of the modelling technique. In this paper, a hybrid multi-technique approach is proposed for maritime heritage preservation and, as case study, the 3D modelling of a 3-meter-long scale model of a historic warship, the "Indomito", is presented. The survey is placed in a wider project aiming to realize the virtual maritime museum of Parthenope University of Naples, for making it available to a wider public and also preserving its cultural heritage. Preliminary results are presented and discussed, highlighting relevant aspects that emerged during the experiment.
\end{abstract}

\section{INTRODUCTION}

In the last decade, the traditional work of archaeologists, art historians, archivists has been progressively transformed owing to the development of three-dimensional (3D) reverse modelling techniques and virtual reality. 3D virtual models of archaeological sites, monuments, finds, exhibits, paintings, etc. have become more and more required and common, since they offer a powerful tool for conducting in-depth analyses, testing different hypotheses, creating databases and archives in a way that was unimaginable some time ago. Moreover, digital models make human Cultural Heritage accessible to a worldwide public and represent an invaluable means for documentation, education and preservation purposes.

The advent of the Cultural Heritage digital era is strictly linked to the development and integration of 3D survey and modelling techniques. Numerous researches and published works give evidence of the scientific and technological progress in this sector, that allowed the realization of models more and more complex and detailed. Image-based and range-based modelling techniques are often combined together for achieving the desired results in terms of accuracy, costs, time of acquisition and data processing.

The improvement in 3D modelling and the consequent proliferation of large 3D datasets have been also associated with the development of methods for processing and visualizing. In web applications, which represent the most effective vector for communicating information and knowledge, multi-resolution and simplification techniques are usually needed for the optimization of geometry, texture and attribute data. The simplification of the original "heavy" digital model is achieved by organizing it into a hierarchy of level-of-details (LOD) progressively compressed (Borgeat et al. 2007).
The Maritime Cultural Heritage field is composed of full-scale historic ships and boats, as well as of models and replicas of famous vessels, of objects and exhibits relating to ships, navigation and travels collected in dedicated museums. This heritage is distributed widely throughout those countries that during the past centuries had based their richness and progress on marine trade and technology. The historic full-scale vessels, some privately owned, others owned and managed by nonprofit trusts or museums, are sometimes still in operation or have been converted themselves in museums. In general, they represent a heritage difficult to manage and preserve because they are built of perishable materials and are "stored" in a hostile environment.

The preservation, communication, restoration and replication in Maritime Cultural Heritage have common topics with the archaeological and cultural patrimony. Additionally, by its nature, this sector shares the technical requirements of the Naval Architecture field as far as the full understanding of the technological and functionality significance is concerned. Historic vessels can embody technological advances, or be fine examples of a particular development in ship and boat building. This contribution investigates the issues related to the 3D modelling and reverse engineering in the Maritime Cultural Heritage sector. A multi-resolution hybrid approach is presented for digital recording of historic ships and scale models. The method consists in a multi-scale image and rangebased technique developed to fulfil issues relating to the restoration, preservation and popularisation of historic vessels as well as requirements for performing more technical analyses. The use of scanning and photogrammetric techniques in conjunction has been frequently employed in the archaeological and Culture Heritage field with remarkable results (Guidi et al. 2009; Voltolini et al. 2007). 


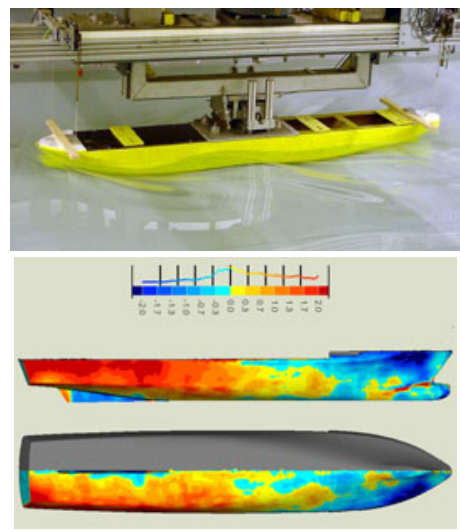

(a)

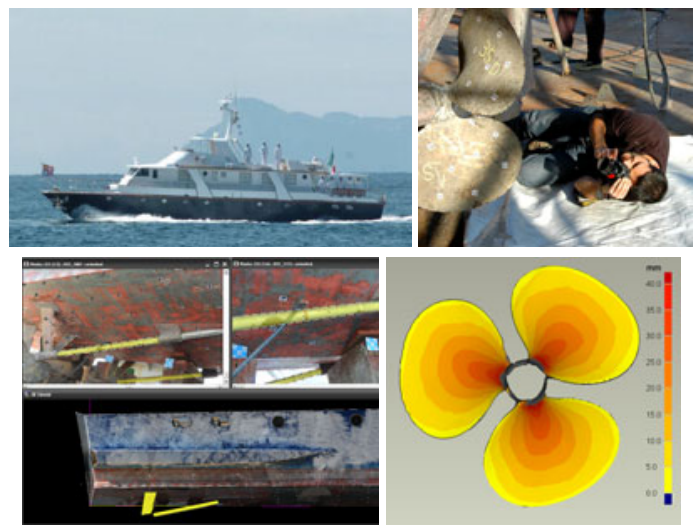

(b)

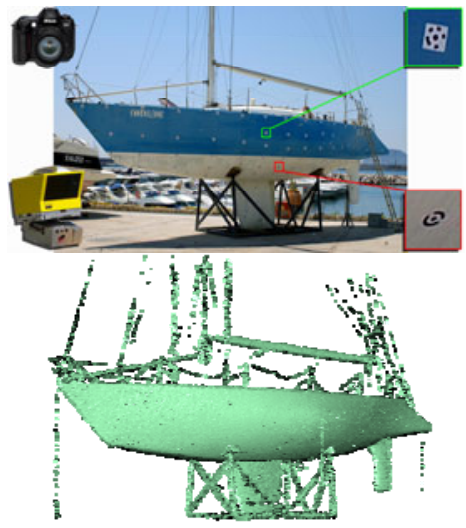

(c)

Figure 1: Examples of maritime applications within the OptiMMA project. a) Symmetry analysis of a towing tank ship model. b) Reverse engineering of the Nave Argo and its screws. c) Reverse engineering of shapes of a sailing boat.

The authors have applied and adapted the integrated method to scale ship models, real vessels or their parts such as screw propellers, appendages etc (Menna and Troisi 2010; Menna et al. 2009; Menna 2009; Ackermann et al. 2008).

In this paper, the $3 \mathrm{D}$ reverse modelling of a 3 -meter-long scale model of a historic warship is discussed as illustrative example. Indeed, the proposed procedure can be extended to the $3 \mathrm{D}$ modelling of full-scale historic vessels as well.

\section{THE OPTIMMA PROJECT}

The case study here presented is part of a wider project called OptiMMA (Optical Metrology for Maritime Applications) involving the Laboratory of Topography and Photogrammetry of Parthenope University. The interdisciplinary project moves from the collaboration with researchers in Naval Architecture with the aim to employ optical metrology and 3D reverse engineering techniques for supporting shipbuilding firms, naval architects and designers, as well as development and research in the maritime field.

Within the OptiMMA project, several applications have been realised in collaboration with different partners (Federico II University, Italian Navy, Maritime Museum of Parthenope University, etc.). Each of the investigations was characterised by different challenges, specific problems and requirements that necessitated a careful planning of the workflow and led to the development of a flexible and general approach.

In the following, some examples are briefly reported for showing the range of applicability of the proposed methodology (figure 1).

The 3D modelling of hull and screw propeller models for towing tank tests was carried out for verifying if the construction and preservation status resulted under the required manufacturing tolerances (Menna and Troisi 2010; Ackermann et al 2008; Menna and Troisi 2007). The 4.6-meter ship model was a 20 -year-old wooden hull and the bronze screw had a diameter of $180 \mathrm{~mm}$. High-precision dense point clouds were obtained, in order to perform different kinds of analyses: (i) symmetry and deformation analyses on the wooden hull (figure 1a); (ii) comparison with the original plans, both for the hull and the screw.

The reverse engineering project of the 81-foot Italian Navy M/Y "Nave Argo" (figure 1b) was performed to study any hull deformations which may have occurred during her lifetime (Menna et al. 2009). The experiment also permitted to verify modifications which were carried out over time (clouts were applied to the hull bottom and bulwarks, the screws were substituted) but that were not recorded or documented.

The multi-technique approach was employed for surveying a 12-meter sailing boat (Fiani et al. 2008; Menna and Troisi 2007). In this case, reverse engineering of shapes (figure 1c) was required since the original plans got lost and the 3D modelling process allowed to retrieve the boat's lines drawing. The case study presented in this contribution has been supported by the Maritime Museum of Parthenope University and represents the first step towards the realization of a digital archive and musealization of the Museum's exhibits.

\section{FOR A PROPER PRESERVATION AND RECORDING OF MARITIME HERITAGE}

Since 1931, the Athens Charter, retrieved in 1964 by the Venice Charter, has defined the basic principles for the conservation and preservation of historic monuments and ancient sites, which, "imbued with a message from the past, remain to the present day as living witnesses of [...] traditions". "The common responsibility to safeguard" human "common heritage" "for future generations" has been recognized, stating that "the principles guiding the preservation and restoration of ancient buildings should be agreed and be laid down on an international basis, with each country being responsible for applying the plan within the framework of its own culture and traditions".

Both Charters focus on monuments and sites ashore, while the 4th European Maritime Heritage - EMH decided to adopt the Venice Charter for maritime heritage in Europe by approving the Barcelona Charter (2003). The Barcelona Charter is a guideline for proper conservation and restoration of historic ships in operation, and realizes the growing interest in the valorisation of European historic and cultural roots.

Europe has always relied on shipping for trade and travel, also before the development of land based infrastructures for mass transportation. Shipbuilding industries have long traditions in Europe, as well generations of European people continue to base their existence and culture on the resources of the sea. The dissemination, preservation and accessibility of those means that moulded the basis of navigation history and human progress, shipping men, merchandise and, above all, culture are of fundamental importance for both "trying to understand the idea of a unified Europe" and "developing safe shipping for the future", (A European vision for the Oceans and the Sea, 2005). 
UNESCO defines heritage as "our legacy from the past, what we live with today, and what we pass on to future generations", something that should be passed from generation to generation because it is valued. With no doubt, this operation of continuity through time can be effectively supported by digital recording and modelling of "those sites, objects and intangible things that have cultural, historical, aesthetic, archaeological, scientific, ethnological or anthropological value to groups and individuals." Such a belief is reinforced by the UNESCO Charter for the Preservation of Digital Heritage: "Resources of human knowledge or expression, whether cultural, educational, scientific and administrative, or embracing technical, legal, medical and other kinds of information, are increasingly created digitally, or converted into digital form from existing analogue resources. [...] Digital materials include texts, databases, still and moving images, audio, graphics, software, and web pages, among a wide and growing range of formats. [...] Many of these resources have lasting value and significance, and therefore constitute a heritage that should be protected and preserved for current and future generations".

Digital recording and 3D modelling of cultural heritage, certainly including historic maritime heritage (ships, as well as ancient harbours), can make them accessible and sharable to possible users and people concerned all around the world. In the light of such a remark, 3D models should be considered themselves as human heritage, whose preservation "requires sustained efforts on the part of governments, creators, publishers, relevant industries and heritage institutions. In the face of the current digital divide, it is necessary to reinforce international cooperation and solidarity to enable all countries to ensure creation, dissemination, preservation and continued accessibility of their digital heritage" (National Library of Australia, 2003).

Even if these issues have been highlighted with emphasis during the last years, clear and rational standards for preservation, recording, digital documentation and reverse modelling have not yet been established.

A valuable effort in this direction has been realized by the English National Historic Ships - NHS, that has created a National Register of Historic Vessels - NRHS including data on British built vessels. The NHS has recognised that to establish proper standards of recording is a crucial step in the heritage sector, as it is something essential in preserving, restoring, conserving and even deconstructing (Kentley et al. 2007a, 2007b).

Even in such cases where the vessel is irremediable damaged and it is not convenient to restore and conserve it, the technological and cultural information it held may be important and need to be preserved. The deconstruction of the ship has to be realised following a systematic dismantling process, during which each element or part of interest has to be properly recorded and archived.

Recording the whole ship or its parts is the only way for ensuring that the real significance and characteristics are captured and conserved. The vessel's shape and structure, interior and exterior arrangement, superstructures, appendices should be documented in sufficient detail. That would allow performing accurate analyses, drawing plans and cross-sections, building precise replica or model.

The minimum, inescapable phase in the "vessel recording" workflow is the execution of a full photographic survey for a comprehensive technical record of the vessel. Pictures of an object are a useful document and tool for describing its relevant characteristics, such as shape, colours, materials, decorations, preservation, etc. If the aim of the recording operation is not only to acquire descriptive data but also to retrieve more technical elements (lines plans, general arrangement plans and construction plans, etc.), specialist knowledge and equipment are required. The degree of knowledge needed, the typology and quantity of equipment necessary depend on the level of detail that the survey has to guarantee and on the time and budget available. These requirements define the approach for carrying out the survey. For example, if the real shape of the surveyed ship is of paramount significance, the conventional assumption that vessels are symmetrical about a longitudinal plane does not hold and the surveyor cannot record only half part of the object. If the survey aims to give evidence of any deformation, alteration or damage, the outcomes will not be corrected or smoothed for approximating the builder's original intentions, but will have to reflect the recorded irregularities. In these examples, both the recording and post processing phases can be time consuming and costly. At the moment, many techniques and equipment can be employed for recording historic ships and the choice of the suitable methodology is largely based on costs. The NHS suggests that, as well as the issue of cost, the selection should also have to be based on important parameters such as accuracy, format of the results, applicability of the method for surveying marine craft, etc. An accuracy of $+/-5 \mathrm{~mm}$ over a range of $50000 \mathrm{~mm}$ should be guaranteed and 3D measurement techniques, like laser scanning, that can assure an accuracy of $1 \mathrm{~mm}$ in $100 \mathrm{~m}$, should be preferred.

A standardization is also required for presenting the results from the recording process. The size of the vessel determines the scale of plans: while conventional imperial scales are 1:48 and 1:96, convenient metric scales are 1:50 and 1:100. For the National Register of Historic Vessels, the NHS recommends to report the resulting measurement information in both Imperial and metric systems (Kentley et al. 2007a). The reason is that most historic English vessels were built according to Imperial measurements, and "by measuring in Imperial units, structures and their relationships may be more readily understood".

Thanks to the modern 3D measurement techniques, an accurate and complete recording of a ship can provide at the same time the traditional 2D drawings and 3D digital models. These products are very attractive for maritime archaeologists as well as Naval Architects, allowing to perform diverse kinds of analyses also with specific naval architecture software. 3D virtual models can permit to answer to scientists' questions about historical advances in shipbuilding and test different hypotheses. They can help in comparing diverse strategies for the preservation or restoration of the surveyed object, allowing to prevent any potentially dangerous action.

\section{ASSESSING THE SIGNIFICANCE OF THE HISTORIC MODEL}

A crucial step in the preservation of historic ships consists in the assessment of what we are seeking to conserve: the assessment of what the vessel is, and why and how it is significant is crucial for deciding the successive actions that have to be done around the ship. The assessment of significance allows to understand the historic and geographical context where the ship operated, establish its contribution to maritime history, technological progress and social and economic development. The assessment of significance becomes of fundamental importance also for 3D modelling of historic vessels, if this process is intended not to be a mere exercise of technology but a useful means for conveying knowledge. 


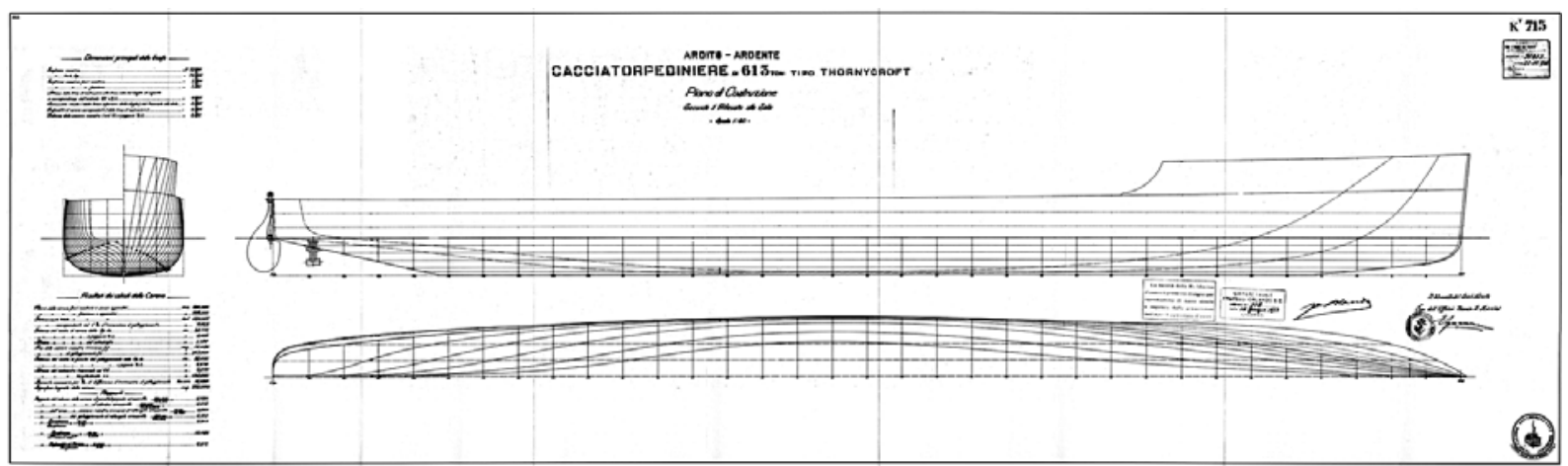

Figure 1: The original lines drawing of "Indomito" class warships.

\subsection{Setting the survey scene}

Since its foundation in 1920 as "Regio Istituto Superiore Navale" (Royal Naval Technical Institute) for encouraging studies related to nautical sciences and maritime economy, the Parthenope University has gathered a wide collection of historic maritime finds. Ranging from scale replica of vessels, instrumentation, educational models, etc., the collection of the Maritime Museum is currently arranged in Villa Doria d'Angri (a two century-year-old villa property of the University) placed on the Posillipo promontory, one of the most impressive places in the Bay of Naples.

The realization of the virtual maritime museum aims both to make it available to a wider public and to preserve its cultural heritage.

\subsection{The "Indomito" destroyer}

A 100-year-old wooden model, an element of the Pattison shipyard's original sample selection, was chosen as first example of 3D modelling for cultural and documentation purposes. The exhibit is the scale model of a torpedo-boat destroyer class, called "Indomito". The chosen model, as well as the others that constitute the Pattison collection of the Parthenope Museum, was employed as sample selection that the shipyard showed to the European Navies. Considering this peculiarity, the 3D reverse modelling of the "Indomito" scale model has a surplus value.
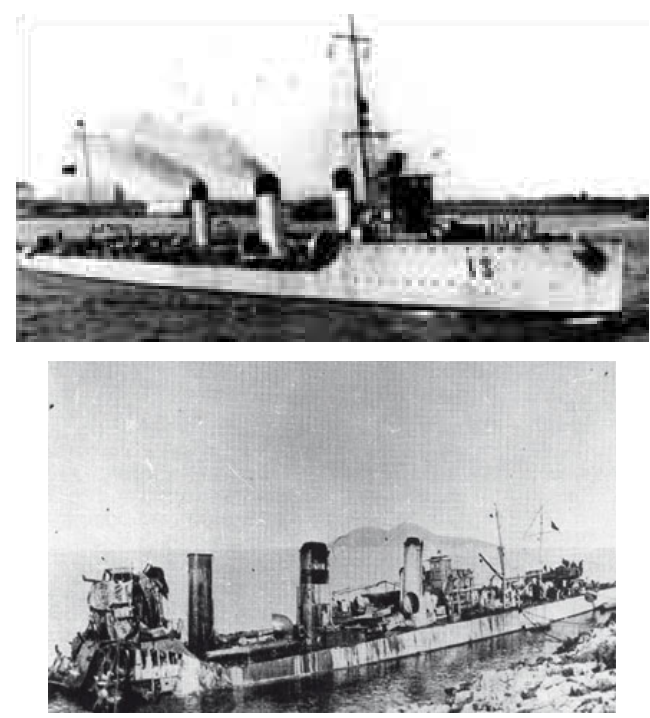

Figure 2: Historic photographs of "three pipes" ships.
The original lines drawing of "Indomito" class warships (figure 1) has been preserved by an Italian association of ship modelmakers (www.anb-online.org). By comparing the virtual model with the project, it would be possible to verify if the wooden model was built according to the original design for the fullscale unit.

The "Indomito" is a torpedo-boat destroyer, built together with the twin ships "Intrepido", "Insidioso", "Irrequieto" at the beginning of twentieth century by the Neapolitan shipyard Pattison. All these ships had a Thornycroft-type hull (with vertical stem, flat stern, external rudder), were characterized by three funnels (this is the reason why they were called "three pipes") and the following main dimensions: Lpp $72.54 \mathrm{~m}, \mathrm{~B}$ $7.34 \mathrm{~m}, \mathrm{~T} 2.66 \mathrm{~m}, \mathrm{D} 4.685 \mathrm{~m}$. Two screw propellers and a $16000 \mathrm{Hp}$ installed power allowed the ship to reach the considerable speed (at that time) of $30 \mathrm{Kts}$. The "three pipes" vessels were employed during the First World War in the Mediterraneum Sea, especially in the low Adriatic Sea (figure 2). One of the "three pipes" ships, the "Intrepido", got hit by a mine and sank by the Albania's costs. In 2007, the wreck of the "Intrepido" was located and an underwater photographic survey was executed (Ruperti 2007) (figure 3).

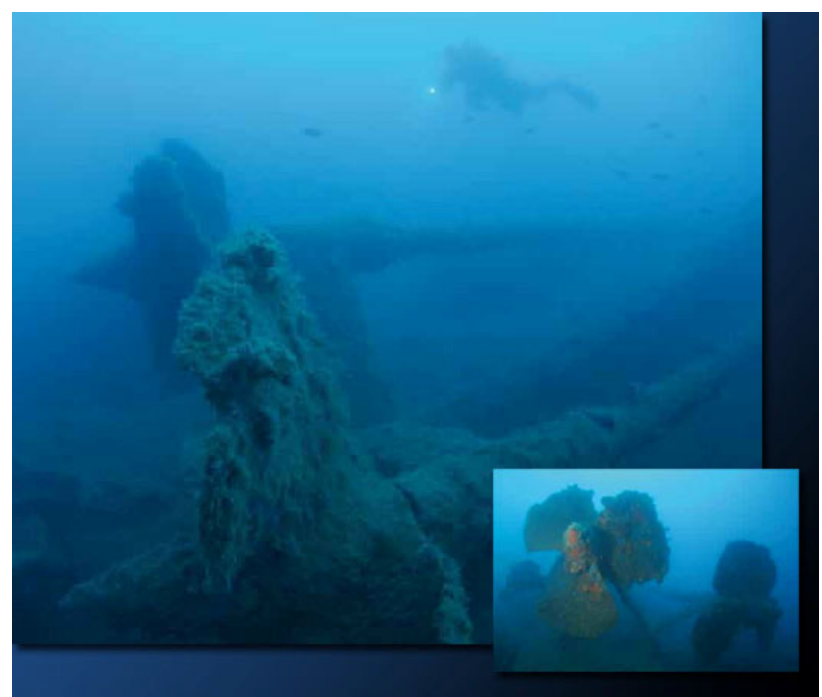

Figure 3: The screws of the "Intrepido" wreck (Ruperti 2007).

\section{3D MODELLING OF THE “INDOMITO” MODEL}

The survey of the "Indomito" model was conducted using a hybrid multi-technique, multi-sensor and multi-resolution approach (figure 4). 


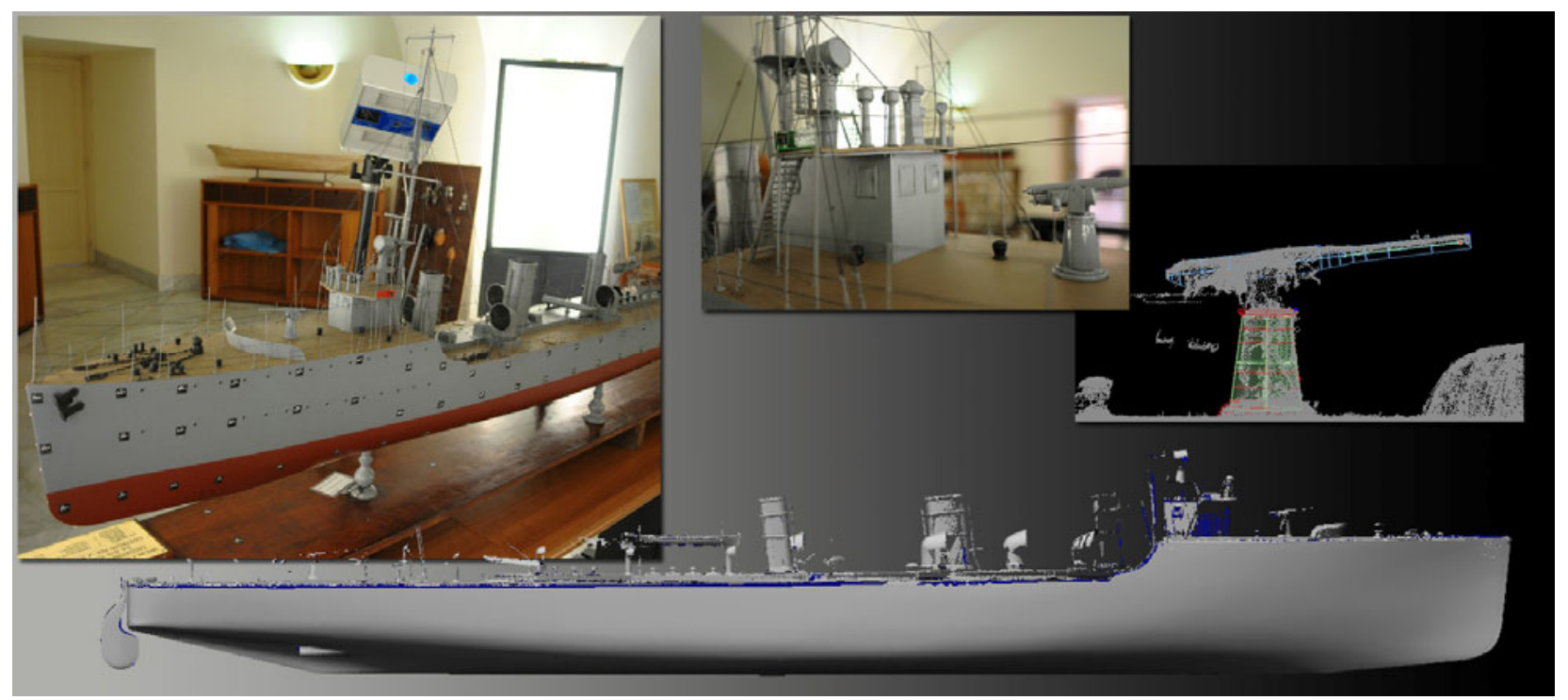

Figure 4: Hybrid survey for 3D modelling of the "Indomito" model of Maritime Museum - Parthenope University of Naples.

\subsection{The hybrid multi-technique approach}

In previous works (Guidi et al. 2009; Menna 2009; Fiani et al. 2008), it has been proved that photogrammetry and laser scanning are equivalent and exchangeable reverse modelling techniques. Active techniques are able to model even complex objects except for the case of wetted or reflective surfaces. On the contrary, photogrammetry can retrieve point clouds but the surveyed object has to be not uniformly painted. In many cases (such as aerial photogrammetry, cultural heritage), the photogrammetric technique is suitable; as far as objects like hulls, screws, appendages, mechanical parts, etc. are concerned, usually it is necessary either to project an artificial pattern on the object or to paint it with a reversible treatment ,e.g. washable tempera (Menna et al. 2009; Ackermann et al. 2008). The area covered or Field-Of-View (FOV) is generally fixed and depends on the distance between the object and the scanner, while in photogrammetry a single camera can cover different areas simply by changing the focal length. In restricted spaces, such as in shipyards, dry or floating docks, etc., the number of scans increases as the covered area is reduced depending on the distance from the object. Consequently, as shown in Fiani et al. (2008) and Guidi et al. (2005) the time needed for scanning grows significantly, also because each scan must have an overlapping area with the adjacent ones. Increasing the number of scans also lessens accuracy of the final point cloud, since each alignment step introduces uncertainty (the law of uncertainty propagation). Moreover, standard registration methods can fail in case of free-form surfaces. Under the same conditions, photogrammetry is surely more flexible, but requires the object being properly arranged (targets and pattern).

In Giudi et al. (2009), Menna (2009) and Fiani et al. (2008) it has been shown that combining photogrammetry and laser scanning methodologies together is advantageous, especially when the survey time-execution is a key factor (as in shipyards, in cases of deconstruction of ancient buildings or vessels, etc.). In this approach an overlapping area is not necessary, reducing the number of scans considerably. Photogrammetry is used to measure code targets previously located on the surface; the targets are also determined in the laser frame and then a similarity transformation is performed to bring the scans in the photogrammetric system. By this process, the model is obtained in a unique reference system.

Despite the unchallenged advantages (limited number of scans, better reliability) of the described method, it can be pointed out that accuracy varies with both the uncertainty in marking target centres on laser point cloud and accuracy of photogrammetric measurements. Combining photogrammetry and laser scanning techniques together involves not only improvement in terms of reliable and quick measurements, but also allows a more efficient and rational use of each methodology. If a high LOD is not required (objects or elements that can be modelled by means of simple geometries such as cubes, spheres, cylinders, etc.) photogrammetry is time-saving. As far as objects, such as ships, characterized by numerous and complex elements (hull, superstructures, sails, mechanical parts, etc.) are concerned, the rational integration of both techniques leads to optimal results. The multi-technique approach also implicates spatial data multiresolution. In Web applications, as well as for documentation and visualization purposes (e.g. virtual museum), optimization of the 3D model is usually convenient, or even necessary. As models produced by reverse modelling techniques are generally high-dens and detailed, they have to be simplified in a proper way. High geometrical resolution is kept only where the topography of the object is significant (e.g. double bended surfaces), whereas few polygons are left in flat areas. The level of texture resolution is chosen depending on the information conveyed. For example high LOD with low texture mapping resolution is used for complex shapes made with uniform and not particularly valuable materials (Guidi et al. 2009).

\subsection{Surveying the "Indomito"}

The survey of the "Indomito" model can be divided into two different surveys: the hull and the main deck with superstructures were surveyed separately and modelled with different methodologies. In the first case, photogrammetry was used to measure coded targets on the model surface, defining a global reference system in which all the scans (obtained with a triangulation scanner) were brought together by means of the similarity transformation. As far as the upper part is concerned, the standard approach with overlapping areas among the scans was selected to join the different point clouds in a common 
frame. The final point cloud of the main deck was then rototranslated in the photogrammetric frame using common $3 \mathrm{D}$ points. Relevant information, summarizing the multi-technique survey, is shown in table 1.

\begin{tabular}{|c|c|c|c|c|c|}
\hline & \multicolumn{2}{|c|}{ MODEL PART } \\
\hline & & & & HULL & MAIN DECK \\
\hline \multirow{15}{*}{ 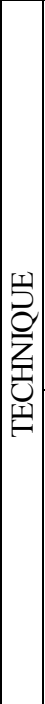 } & \multirow{9}{*}{ 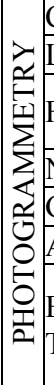 } & \multicolumn{2}{|l|}{ CAMERA } & Nikon D300 & Nikon D300 \\
\hline & & \multicolumn{2}{|l|}{ LENS } & $35 \mathrm{~mm}$ & $20 \mathrm{~mm}$ \\
\hline & & \multirow{2}{*}{\multicolumn{2}{|c|}{ FLASH }} & Nikon & Nikon \\
\hline & & & & SB600+SB800 & SB600+SB800 \\
\hline & & \multicolumn{2}{|l|}{ N. PHOTOS } & 80 & 35 \\
\hline & & \multicolumn{2}{|l|}{ GSD } & $0.2 \mathrm{~mm}$ & $0.3 \mathrm{~mm}$ \\
\hline & & \multicolumn{2}{|c|}{ AVERAGE DISTANCE } & $1.0 \mathrm{~m}$ & $1.0 \mathrm{~m}$ \\
\hline & & \multirow{2}{*}{$\begin{array}{l}\text { EXECUTION } \\
\text { TIME }\end{array}$} & Targeting & $6 \mathrm{~h}$ & $0 \mathrm{~h}$ \\
\hline & & & Photo & $2 \mathrm{~h}$ & $<1 \mathrm{~h}$ \\
\hline & \multirow{5}{*}{ 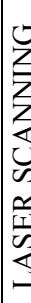 } & \multicolumn{2}{|l|}{ SCANNER } & $\begin{array}{l}\text { NextEngine } \\
\text { triangulation } \\
\text { scanner }\end{array}$ & $\begin{array}{l}\text { DOptical } \\
\text { structured } \\
\text { scanner }\end{array}$ \\
\hline & & \multicolumn{2}{|l|}{ N. SCANS } & 32 & 60 \\
\hline & & \multicolumn{2}{|c|}{ RESOLUTION } & $0.34 \mathrm{~mm}$ & $0.2 \mathrm{~mm}$ \\
\hline & & \multicolumn{2}{|c|}{ AVERAGE DISTANCE } & $0.5 \mathrm{~m}$ & $1.0 \mathrm{~m}$ \\
\hline & & \multicolumn{2}{|c|}{ FIELD OF VIEW } & $250 \mathrm{~mm} \times 300 \mathrm{~mm}$ & $250 \mathrm{~mm} \times 250 \mathrm{~mm}$ \\
\hline & -1 & \multicolumn{2}{|c|}{ EXECUTION TIME } & $8 \mathrm{~h}$ & $6 \mathrm{~h}$ \\
\hline
\end{tabular}

Table 1: Main characteristics of the "Indomito" model survey.

\subsection{Hull Survey}

Before beginning the survey, about 200 circular coded targets were positioned on the hull surface, using removable notaggressive glue to not damage the model paint. Such shrewdness was very time-consuming, since it was preferable not to use adhesive targets.

The photogrammetric survey was conducted by means of a 12 Mega Pixels Nikon D300 DSLR (Digital Single Lens Reflex) camera mounting a $35 \mathrm{~mm}$ lens. 80 photos were necessary to cover both the port and the starboard sides, taking care to assure a proper network with stereoscopic convergent images. The average distance of the camera from the model was about $1 \mathrm{~m}$, resulting in a $0.2 \mathrm{~mm}$ pixel size in the object space (Ground Sample Distance - GSD). In order to achieve a homogeneous lighting (necessary to extract the texture in the successive step), two flashes (Nikon SB600 and Nikon SB800), in wireless mode, were employed. Some calibrated bars were imaged, in different positions and orientations (for redundancy), for dimensioning the photogrammetric measurements. The determination of the circular coded target centres was done almost automatically by means of Photomodeler EOS 5.2.3 software, giving a maximum spatial residual (one sigma) less than $0.1 \mathrm{~mm}$ on the spatial coordinates. The measured targets, all in the same reference frame, were successively used to align the scans. A low-cost triangulation scanner, the "NextEngine" 3D Scanner, was used to obtain a dense point cloud of the model's hull. More than 30 scans at an average distance of 0.5 $\mathrm{m}$ were executed; only a small overlapping area among them was required in order to guarantee a complete coverage. About 8 working hours were necessary to position the instrument in the different stations and obtain the point clouds.

For each point cloud, the centres of coded targets were measured in each scan own frame; then the same coded targets in the photogrammetric frame were used to compute the seven parameters of the similarity transformation. In this way all the point clouds were transformed into the same global system. The maximum residual on the target centres was less then $0.15 \mathrm{~mm}$, that is approximately the accuracy declared by the scanner factory. Once the alignment procedure was completed, the registered point cloud (about 14 million points) was triangulated to generate a mesh; the number of points was then reduced depending on the surface curvature (optimization).

The coded targets were automatically removed from the triangulated mesh surface using a simple algorithm that works in two steps: (i) removal of the vertexes of the mesh neighbouring the photogrammetric centroid; (ii) filling of the hole created in the first step.

To seek the model own reference frame, some points along the keel and the stem were marked and measured by photogrammetry. The centreplane and longitudinal axis were determined using the least square procedure; consequently, the baseplane and the transversal plane were defined orthogonally to the centreplane.

Measurements on the 3D laser model have shown that the main characteristics of "Indomito" historic model (Lpp 2.895 m, B $0.287 \mathrm{~m}, \mathrm{D} 0.192 \mathrm{~m}$ ) do not completely follow full-scale ship dimensions (only the scale length ratio is in agreement with the supposed scale 1:25).

To compare the laser mesh with the original body plan, the 3D model was reduced at the drawing scale (1:50). In this way, using the model own reference system, each measurement refers to the body plane and can be compared directly with it (e.g. by plotting it on the lines drawing in paper format). Afterwards, the triangular mesh was sectioned in specific positions to generate 2D lines of interest, such as waterlines, buttocks etc., while the original paper transversal plan was digitalized and then rectified (figure 5).

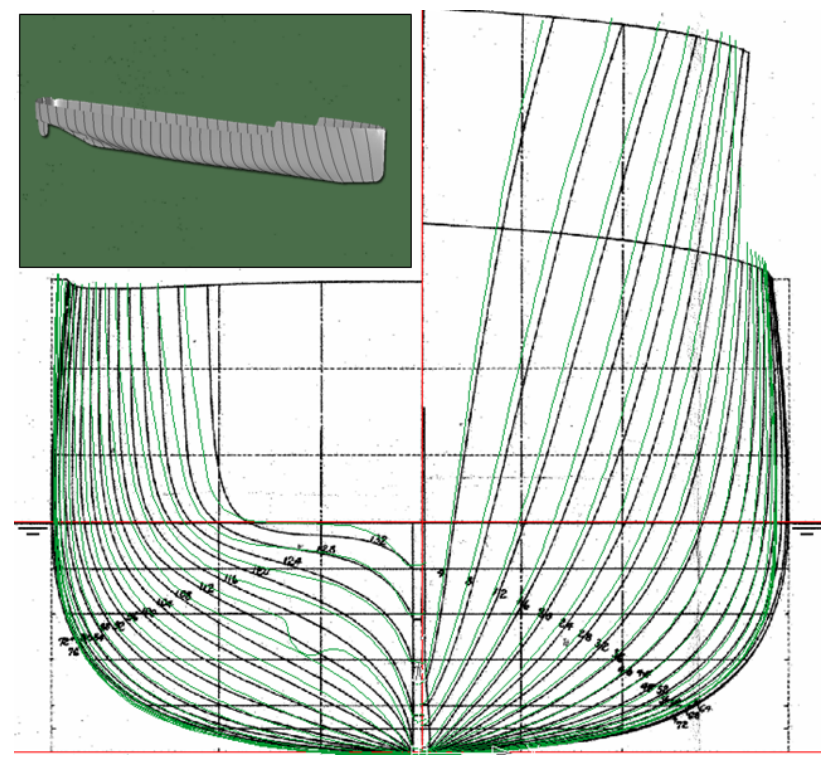

Figure 5: 2D comparison between cross sections of the scanned model and the original lines drawing.

The comparison has demonstrated that the historic model is larger than the original body plan; the greatest differences have been found in starboard bulwark. As a significantly torsion of the wooden model was suspected, a symmetry analysis was also carried out, by mirroring the port side and comparing it with the starboard side. Significant differences can be highlighted especially as far as bulwarks are concerned (figure 6).

These outcomes were expected as the "Indomito" model was built only for representative purposes; no manufacturing tolerances were required as for example in the case of towing 
tank models (Ackermann et al. 2008). Moreover, during its lifetime, many restoration activities have been carried out on the wooden model probably changing its original shape.

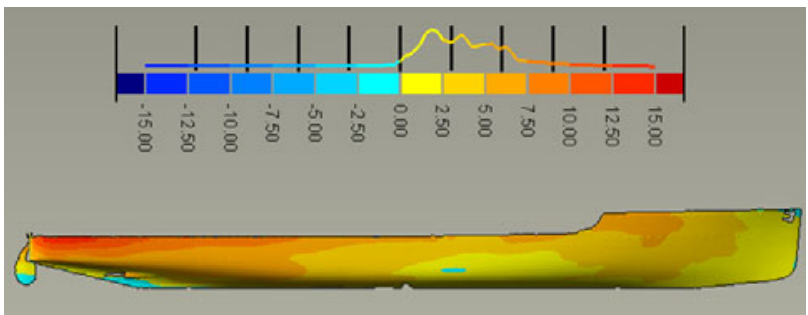

Figure 6: Symmetry analysis of the hull (mm).

\subsection{Main deck and superstructures survey.}

Many issues emerged from the survey of the main deck and superstructures. Noticeable technical difficulties arose since this part of the model presented numerous miniature elements. The objects, very close to each other, caused critical, unavoidable occlusions; elements such as masts, shrouds, bulwark stanchions, manropes and guard-rails produced shadows and artefacts in the point cloud (figure 7).
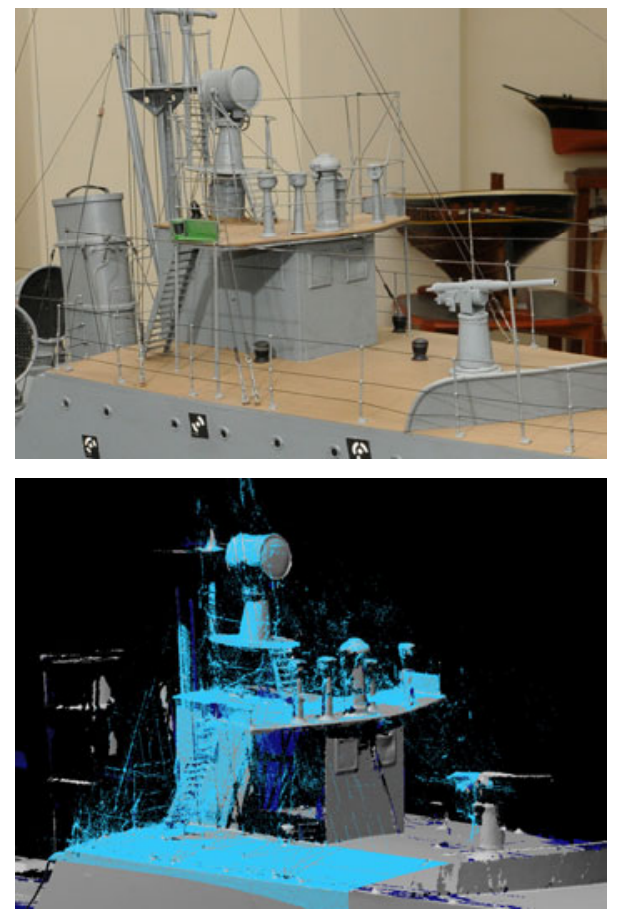

Figure 7: Noise and artefacts caused by shrouds.
For modelling small objects the only affordable technology is triangulation scanners or fringe projectors, able to resolve small details. Since the NextEngine scanner was not suitable in this case since it took too long time for scanning (about 120 seconds for scan), a low cost fringe projector scanner, the "Optical RevEng", was chosen for its speed in measuring point clouds. Due to the high complexity of the model's deck with all its elements, numerous scans had to be acquired (about 60). The final global point cloud after scan alignment counted about 50 million points. Despite the elevated number of scans, the mesh was characterised by various gaps and shady areas (figure 8 ).

The issue of surveying and modelling objects full of small elements and details has been faced in literature by many authors. For examples, in Guidi et al. (2007), a Laser Radar was employed for the digital acquisition of the "Plastico di Roma Antica". In all the cases where it is not possible to perform a 360-degree scan, the acquired 3D model suffers from the effects due to the high density and nearness of small items and a massive and time-consuming modelling phase is necessary.

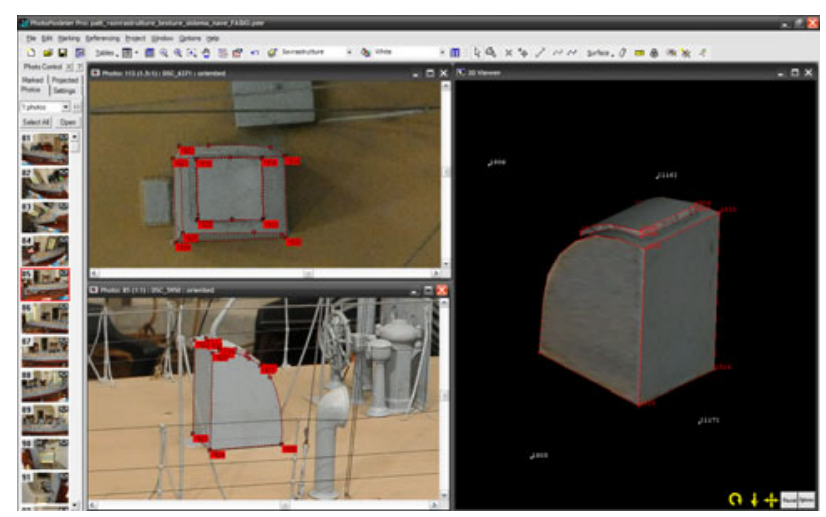

Figure 9: Photogrammetric modelling of simple geometric features.

Overcoming these practical difficulties would require to employ a high-cost equipment like a laser scan arm that anyway are not suitable for recording very thin elements such as masts, shrouds and bulwark stanchions. These objects and simple solids such as wind catchers and cabin R.T. (figure 9) were therefore modelled with photogrammetry by measuring only few points and geometric primitives instead of modelling them by simplifying a dense point cloud. In this case, the camera (Nikon D300) was the same employed to survey the model's hull, while the lens chosen was a $20 \mathrm{~mm}$. The 35 pictures taken were used to obtain a photorealistic texture that was mapped on the laser mesh (figure 10).
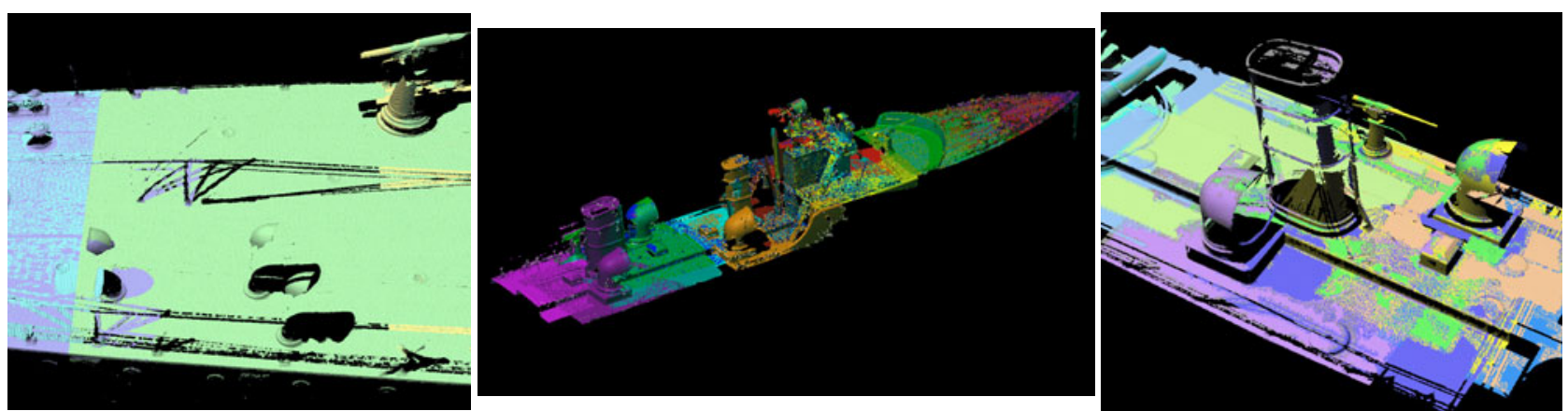

Figure 8: The mesh of the main deck is characterised by gaps and shady areas. 


\section{CONCLUSIONS}

In this paper, a low-cost procedure for 3D modelling of complex objects, such as models of historic ships, has been presented. Its reliability and effectiveness for maritime heritage applications has been discussed. Preliminary results of the survey of a historic model ("Indomito" torpedo-boat destroyer) have been shown, highlighting the relevant aspects that emerged during the experiment. Further improvements will be brought to completion in order to obtain a full "Indomito" 3D model (including detailed texture and superstructures).

The proposed procedure can be used both for obtaining a $3 \mathrm{D}$ virtual model for physical replicas or technical analyses (symmetry, hydrostatics, lines drawing) and for creating digital database containing significant elements (hull, funnels, weapons, life boats, screws, etc.) characterising the object of interest.

Despite the rapid progress of technologies and instrumentations, $3 \mathrm{D}$ reverse engineering and modelling of complex objects such as full-scale or model ships is still a complex process. Multiintegration of different technologies is usually required for retrieving all the necessary data for a complete $3 \mathrm{D}$ modelling, with a consequent increase of costs. The need of low-cost solutions is crucial for making feasible the $3 \mathrm{D}$ digital recording of maritime heritage.

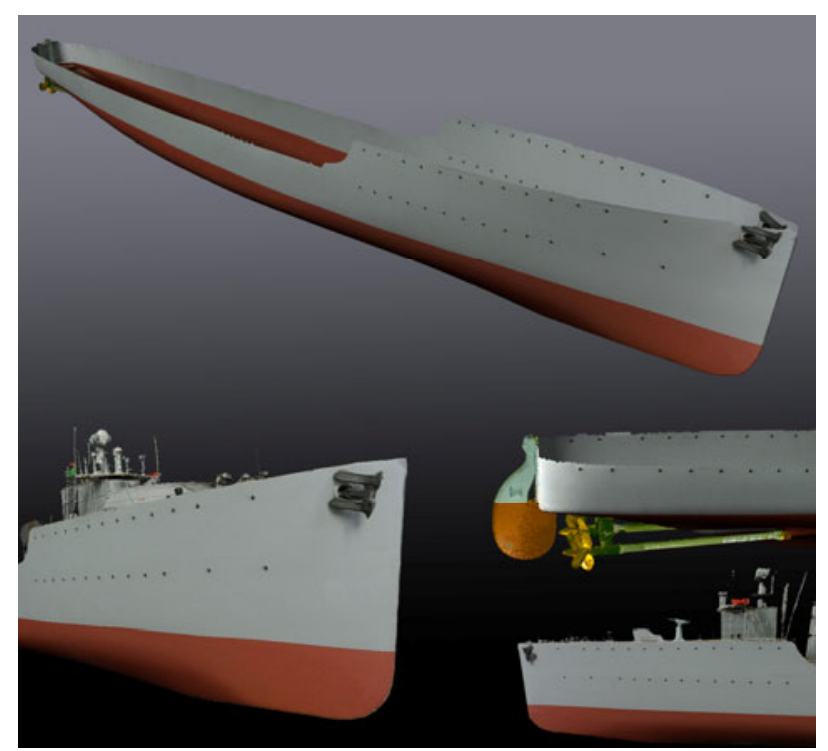

Figure 10: Photorealistic texture mapping of bow and forecastle deck.

\section{REFERENCES}

Ackermann, S., Menna, F., Scamardella, A., Troisi, S., 2008: Digital photogrammetry for high precision 3D measurements in shipbuilding field. $6^{\text {th }}$ CIRP International Conference on ICME, Intelligent Computation In Manufacturing Engineering, Naples.

A European vision for the Oceans and the Sea, 2005. Common European Maritime Heritage Congress. http://www.europeanmaritime-heritage.org/

Borgeat, L., Godin, G., Blais, F., Beraldin, J.A., Massicotte P., Poirier, G., 2007: Visualizing and analyzing large and detailed 3D datasets. Proc. of 2nd ISPRS International Workshop 3DARCH 2007, ETH Zurich, Switzerland, 12-13 July 2007.
Fiani, M., Menna, F., Troisi, S., 2008: Integrazione di tecniche di fotogrammetria laser scanning per la modellazione 3D della carena di una imbarcazione. Bollettino della Società Italiana di Fotogrammetria e Topografia, $n^{\circ} .1$, pp. 39-58

Guidi, G., Remondino, F., Russo, M., Menna, F., Rizzi, A., Ercoli, S., 2009: A multi-resolution methodology for the 3D modeling of large and complex archaeological areas. International Journal of Architectural Computing, Vol.7(1), pp. $40-55$

Guidi, G., Frischer, B., Lucenti, I., 2007: Rome reborn Virtualizing the ancient imperial Rome. Proc. Proc. of 2nd ISPRS International Workshop 3D-ARCH 2007, ETH Zurich, Switzerland, 12-13 July 2007

Guidi, G., Micoli, L.L., Russo, M. 2005. Boat's hull modeling with low-cost triangulation scanners. Videometrics VIII - Proc. of SPIE-IS\&T Electronic Imaging, SPIE, 5665: 28-39

Kentley, E., Stephens, S., Heighton, M., 2007a: Recording Historic Vessels. Understanding Historic Vessels Volume 1. National Historic Ships.

http://www.nationalhistoricships.org.uk/

Kentley, E., Stephens, S., Heighton, M., 2007b: Deconstructing Historic Vessels. Understanding Historic Vessels Volume 2. National Historic Ships.

http://www.nationalhistoricships.org.uk/

Menna, F., Troisi, S., 2010: Low cost reverse engineering techniques for 3D modelling of propellers. International Archives of Photogrammetry, Remote Sensing and Spatial Information Sciences, Vol. XXXVIII, Part 5 Commission V Symposium, Newcastle upon Tyne, UK. 2010

Menna, F., Ackermann, S., Nocerino, E., Scamardella, A., Troisi, S., 2009: Digital photogrammetry: a useful tool for shipbuilding applications. 13th Congress of Intl. Maritime Assoc. of Mediterranean IMAM 2009, İstanbul

Menna, F., 2009: Metodologie e Tecniche per la Modellazione Tridimensionale Inversa. Ph.D. thesis Parthenope University of Naples

Menna, F., Troisi, S., 2007: Photogrammetric 3D modelling of a boat's hull. VIII Conference on Optical 3D Measurement Techniques - Gruen and Kahmen (Eds), Vol. II, pp. 347-354, July 9-12, 2007, Zurich, Switzerland

National Library of Australia, 2003: Guidelines for the preservation of digital heritage. UNESCO document CI2003/WS/3.

http://unesdoc.unesco.org/images/0013/001300/130071e.pdf

Ruperti, F., 2007: Intrepido fino in fondo. www.iantdexpeditions.com/spedizioni/in2007/intrepido.pdf

Voltolini, F., Rizzi, A., Remondino, F., Girardi, S., Gonzo, L., 2007: Integration of non-invasive techniques for documentation and preservation of complex architectures and artworks. Proc. Proc. of 2nd ISPRS International Workshop 3D-ARCH 2007, ETH Zurich, Switzerland, 12-13 July 2007

The Barcelona Charter, 2003. http://www.european-maritimeheritage.org/ 